\title{
Simulated Long-Term Driving Performance before and after Uvulopalatopharyngoplasty
}

Per-Olle Haraldsson, Christer Carenfelt, Hans E Persson and Charlotte Sachs, Karolinska Hospital, Stockholm Sweden Jan Törnros, Swedish Road and Traffic Research Institute, Linköping, Sweden

Reprint from ORL1991;53, pp 106-110 



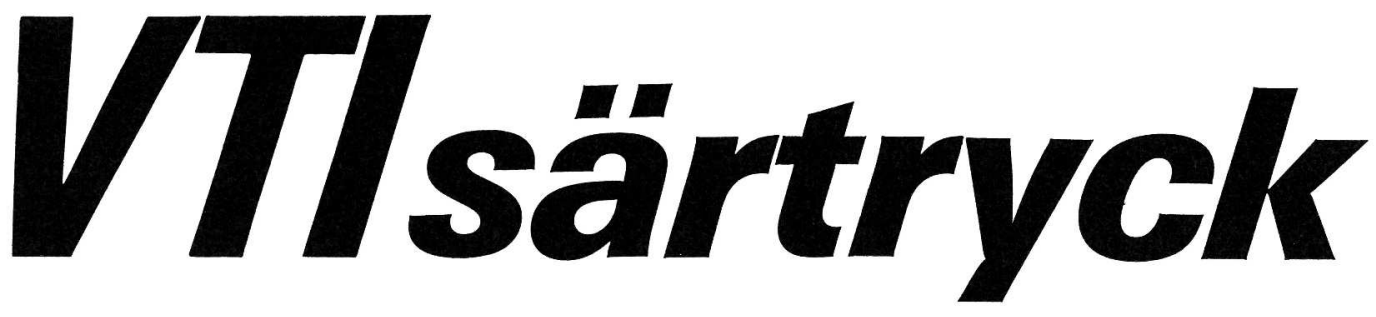

\section{Simulated Long-Term Driving Performance before and after Uvulopalatopharyngoplasty}

Per-Olle Haraldsson, Christer Carenfelt, Hans E Persson and Charlotte Sachs, Karolinska Hospital, Stockholm Sweden Jan Törnros, Swedish Road and Traffic Research Institute, Linköping, Sweden

Reprint from ORL1991;53, pp 106-110 


\title{
Simulated Long-Term Driving Performance before and after Uvulopalatopharyngoplasty
}

\author{
Per-Olle Haraldsson ${ }^{\mathrm{a}}$, Christer Carenfelt ${ }^{\mathrm{a}}$, Hans E. Persson ${ }^{\mathrm{b}}$, Charlotte Sachs $^{\mathrm{c}}$, Jan Törnros ${ }^{\mathrm{d}}$ \\ Departments of a Otorhinolaryngology, ${ }^{b}$ Neurophysiology and ${ }^{c}$ Neurology, Karolinska Hospital, Stockholm; \\ ${ }^{\mathrm{d}}$ Swedish Road and Traffic Research Institute, Linköping, Sweden
}

Key Words. Driving test $\cdot$ Driving performance $\cdot$ Automobile accidents $\cdot$ Sleep apnea

\begin{abstract}
To investigate whether automobile drivers with the clinical features of sleep apnea syndrome (SAS) perform worse than controls in a simulated long-term test drive, and to see if their driving improves after uvulopalatopharyngoplasty (UPPP), 15 male drivers with SAS, suffering from sleep spells whilst driving, and 10 matched controls without a history of SAS or hypersomnia at the wheel were tested in an advanced driving simulator. Brake reaction time, lateral position deviation and off-road episodes were measured during a 90-min rural drive at twilight conditions. The clinical evaluation was made by a questionnaire scoring symptoms of snoring, sleep disturbances and diurnal sleepiness before and after surgery. Before UPPP the patient group showed impaired performance in all three effect measures compared to controls. UPPP resulted in improved reaction time performance (average mean improvement: $0.5 \mathrm{~s}$, average 90th percentile improvement $0.8 \mathrm{~s}$ ). Furthermore, 12 of the 15 patients reported a marked improvement regarding sleepiness whilst driving. For these clinically successful cases the number of off-road episodes decreased substantially. We conclude that most patients improve their long-term driving performance as a result of UPPP.
\end{abstract}

\section{Introduction}

An excessive tendency to fall asleep whilst automobile driving is a common complaint of patients with the sleep apnea syndrome (SAS). Some $50 \%$ of patients with clinical symptoms of the syndrome report this complaint, compared to less than $1 \%$ in matched controls [1]. Sleep apneics perform poorly in psychomotor and cognitive tests $[2,3]$, but not until recently has it been reported that automobile accidents [4, 5], especially single-car accidents [1], are overrepresented in sleep apnea drivers. Those reporting sleep spells at the wheel predominate [1]. According to Aldrich et al. [6], as many as 6,500 annual automobile accident deaths in USA might be due to falling asleep at the wheel. SAS is probably one of the important contributing factors to these fatalities.

An early polysomnographic definition suggests that SAS prevails if there are 30 or more apneic episodes with a minimum duration of $10 \mathrm{~s}$ during $7 \mathrm{~h}$ sleep, or an apnea index (events/h) of 5 or more [7]. However, another clinical definition is given by the Association of Sleep Disor- der Centers suggesting three findings to characterize SAS; multiple (without cutting scores) obstructive or mixed sleep apneas with repetitive episodes of loud snoring and excessive daytime sleepiness [8]. When the respiratory obstruction is generated at the level of oropharynx, a uvulopalatopharyngoplasty (UPPP) should be considered. One generally accepted arbitrary level of success of surgical treatment is a more than $50 \%$ reduction of the number of apneas [9]. Following UPPP, such a reduction can be expected in $50-80 \%$ of the cases [9-11], but even many of the remaining cases improve clinically. This incongruity between the patients' experience of wellbeing and objective sleep data, indicating persistence of the disorder, has not fully been explained.

At the Swedish Road and Traffic Research Institute a driving simulator test has been developed to detect drivers suffering from hypersomnia at the wheel [12]. In the present study, patients with SAS according to the clinical definition, complaining of sleepy spells whilst driving participated in test drives, with the hypothesis that UPPP would improve the driving performance. 


\section{Subjects and Methods}

\section{Definitions and Selection of Subjects}

Fifteen male drivers, selected in the age group 30-69 years, who claimed to have habitual sleep spells whilst driving, were consecutively selected from patients with the clinical triad of habitual symptoms that characterizes the obstructive SAS: heavy snoring, sleep disturbances (reported sleep apneas (14/15) and/or awakenings (12/15), despite no difficulty falling asleep) and excessive daytime sleepiness with sleep attacks $[7,8,13]$. In the questionnaire used [1], the symptoms were neglected if scored 'never' or 'seldom', but considered as habitual, if they recurred 'often' or 'always'. Furthermore, if multiple episodes of obstructive or mixed apnea were found, preor postoperatively, during a defined nap or all-night polysomnography, the diagnosis was designated as SAS, after a previous consensus definition [8]. Ten age-matched [median age $54(46-64)$ vs. 55 (4262 ) years] male volunteers, with similar experience of car driving were selected as controls. They were not subjected to sleep studies, but denied hypersomnia at the wheel and habitual recurrence of the aforesaid triad of symptoms associated with SAS.

Postoperative clinical success, as regards traffic risks, was defined on the questionnaire as a denial (never, seldom) of sleep spells at the wheel.

\section{Clinical and Polysomnographic Examinations}

All 15 patients had a standard preoperative ENT examination, followed by fiberoptic rhinolaryngoscopy during voluntary snoring and Müller's maneuver. A static cephalometry of posterior airway space (PAS), and mandibular plane to hyoid bone (MP-H), was performed. They were considered as pathological, if $<11 \mathrm{~mm}$ and $>15 \mathrm{~mm}$, respectively [14]. Based on these findings the level of obstruction was classified according to Fujita [15]. All patients were examined by a neurologist to exclude narcolepsy. None of the included patients had cataplexia, sleep paralysis, a positive family history, or a multiple sleep latency test consistent with narcolepsy. A body mass index (BMI) $>29 \mathrm{~kg} / \mathrm{m}^{2}$ indicating overweight [16], blood pressure after $5 \mathrm{~min}$ of rest in the sitting position, using a triple-seized sphymanometer cuff, and treatment for hypertension, if any, was recorded. A standard ECG was performed. All patients were subjected to a daytime polysomnography (PSG) following one night of sleep deprivation [17]. This examination included registrations of EEG, EOG, submental EMG, and respiration (with thermistors in nostrils and mouth and a thoracic strain gauge), and lasted for $1 \frac{1 / 2-2}{h}$. The examination was repeated if the first one failed due to inadequate sleep. Total sleeping time, sleep stages, number and duration of obstructive, central or mixed apneas, and total apnea time were calculated.

The polysomnographic data were used to identify obstructive sleep apnea. The number of apneas per $60 \mathrm{~min}$ of sleep was considered for estimation of an apnea index (AI). Postoperatively, we also had access to all-night PSG, which was performed when an AI $<5$ was found either pre- or postoperatively in the nap studies. This all-night PSG included all the sleep parameters for the daytime PSG, plus transcutaneous oxymetry.

\section{Driving Simulator Test}

The advanced driving simulator at the Swedish Road and Traffic Research Institute was used. The equipment, computer program, and the test run have previously been described [12]. A monotonous drive at about $90 \mathrm{~km} / \mathrm{h}(55 \mathrm{mph})$ on a one-lane, narrow $(3.5 \mathrm{~m})$ curved road at twilight, intended to provoke sleepiness was used, during which the driving performance was measured. The subjects were instructed to drive, if capable, for a period of $90 \mathrm{~min}$. The drivers were subjected to 25 visual brake reaction stimuli during the 90-min drive. The lateral position of the vehicle was sampled twice per second, and the standard deviation was calculated for each 5-min period. Performance data were collected during the total drive, and subsequently subjected to analysis. During the test the drivers were observed and videotaped using infrared-sensitive television. Etfect measures thus included brake reaction time (BRT), lateral position deviation (LPD), and frequency of off-road episodes, as previously described [12].

\section{Surgical Procedure}

All patients had a UPPP performed under general anesthesia, using a slight modification of the technique described by Dickson et al. [10]. Three patients (No. 2, 4, 13) complained of decreased nasal patency and also had their nasal obstruction corrected.

\section{Design and Testing Procedure}

Preoperatively the 15 selected patients were subjected to the driving test and compared with 10 controls. Two patients were retested preoperatively to verify consistency of the test. Three months following surgery, symptomatology was reassessed, by using the same questionnaire. The patients were polysomnographically reexamined, either by nap study or all-night PSG after surgery. Our patients and 5 of the controls were subjected to a retest, which for each subject was identical to the preoperative one. Primary performance data, for the controls thus selected for evaluation of consistency, did not differ significantly from those not retested. At the second test, driving performance data were assessed without knowledge of the clinical outcome, as evaluated by the questionnaire.

\section{Statistical Methods}

For comparison of unpaired and paired data of BRT and LPD, based on the arithmetic mean and the 90th percentile values for each driver, Student's $t$ test was used one-tailed. To compare number of drivers off-road (independent samples), Fischer's exact test was used. For comparison of number of episodes off-road (related samples), Sign test was used.

\section{Results}

All the 15 patients selected, showing a complete clinical picture of SAS, had multiple obstructive or mixed sleep apneas (table 1$)$. Nine $(60 \%)$ patients were overweight (mean $98 \mathrm{~kg}$, range $71-123)$ and $9(60 \%)$ used antihypertensives. Cephalometrical measures were consistent with SAS (PAS $<11 \mathrm{~mm}$ in 6 cases and MP-H $>15 \mathrm{~mm}$ in all cases) and the level of respiratory obstruction was confined to the soft palate, tonsils and tongue base (Fujita I, IIa, Fujita IIb) in all patients.

Following surgical treatment, 12 of 15 patients ( $80 \%)$ reported a marked improvement of sleep attacks at the wheel, while 3 patients were essentially unchanged (table 1). Except for these 3 cases, only 1 other patient 
Table 1. Clinical characteristics of 15 male patients selected for driving test before and after UPPP

\begin{tabular}{|c|c|c|c|c|c|c|c|c|}
\hline \multirow{2}{*}{$\begin{array}{l}\text { Patient } \\
\text { No. }\end{array}$} & \multirow{2}{*}{$\begin{array}{l}\mathrm{BMI} \\
\mathrm{kg} / \mathrm{m}^{2}\end{array}$} & \multirow{2}{*}{$\begin{array}{l}\text { Blood } \\
\text { pressure }\end{array}$} & \multicolumn{2}{|c|}{ Apnea index ${ }^{a}$} & \multicolumn{2}{|c|}{ Sleep disturbances ${ }^{b, c}$} & \multicolumn{2}{|c|}{ Sleep spells whilst driving ${ }^{b}$} \\
\hline & & & pre & postop & pre & postop & pre & postop \\
\hline 1 & 33.5 & $165 / 105^{\mathrm{d}}$ & 0 & $5^{\mathrm{e}}$ & 4 & 1 & 4 & 2 \\
\hline 2 & 26.2 & $160 / 110$ & 23 & 11 & 4 & 1 & 4 & 2 \\
\hline 3 & 26.3 & $140 / 80$ & 40 & 27 & 3 & 1 & 4 & 2 \\
\hline 4 & 37.6 & $165 / 95$ & 4 & $20^{\mathrm{e}}$ & 4 & 2 & 4 & $3^{f}$ \\
\hline 5 & 32.5 & $115 / 80^{\mathrm{d}}$ & 50 & $0^{\mathrm{e}}$ & 4 & 1 & 3 & 1 \\
\hline 6 & 24.0 & $130 / 80$ & 25 & $0^{\mathrm{e}}$ & 4 & 2 & 4 & 2 \\
\hline 7 & 31.1 & $180 / 110^{\mathrm{d}}$ & 49 & 112 & 3 & 1 & 3 & 1 \\
\hline 8 & 37.5 & $150 / 100^{\mathrm{d}}$ & 50 & 43 & 4 & 2 & 4 & $3^{f}$ \\
\hline 9 & 33.5 & $140 / 90$ & 57 & 58 & 3 & 1 & 4 & 1 \\
\hline 10 & 30.2 & $140 / 90^{\mathrm{d}}$ & 69 & 36 & 4 & 2 & 4 & 1 \\
\hline 11 & 31.4 & $155 / 110^{d}$ & 14 & 2 & 4 & 2 & 4 & 1 \\
\hline 12 & 28.1 & $170 / 95^{\mathrm{d}}$ & 31 & 52 & 4 & 2 & 4 & 2 \\
\hline 13 & 26.0 & $150 / 110^{d}$ & 105 & 68 & 4 & 3 & 4 & $3^{f}$ \\
\hline 14 & 29.3 & $150 / 100^{d}$ & 103 & 5 & 4 & 2 & 3 & 1 \\
\hline 15 & 23.4 & $140 / 80$ & 66 & 53 & 3 & 3 & 4 & 2 \\
\hline
\end{tabular}

Estimated from a daytime polysomnographic nap study.

Score $1=$ Never; 2 = seldom; 3 = often; 4 = always on questionnaire.

The highest scores for sleep apnea or awakenings are given pre- and postoperatively from questionnaire.

Using antihypertensive drugs.

Postoperative all-night polysomnography.

Patients 4,8 and 13 were clinical failures according to questionnaire.

Table 2. Results of test drive comparing BRT and LPD before and after UPPP

\begin{tabular}{|c|c|c|c|c|c|c|c|}
\hline & \multicolumn{3}{|c|}{ Preoperative test } & \multirow[t]{2}{*}{$\mathrm{p}$} & \multicolumn{3}{|l|}{ Retest } \\
\hline & $\begin{array}{l}\text { controls } \\
(\mathrm{n}=10)\end{array}$ & $\mathrm{p}$ & $\begin{array}{l}\text { SAS preop } \\
(\mathrm{n}=14)^{\mathrm{b}}\end{array}$ & & $\begin{array}{l}\text { SAS postop } \\
(\mathrm{n}=14)\end{array}$ & $\mathrm{p}^{\mathrm{a}}$ & $\begin{array}{l}\text { controls } \\
(\mathrm{n}=5)\end{array}$ \\
\hline Mean BRT, s & $1.31 \pm 0.20$ & $<0.01$ & $1.89 \pm 0.59$ & $<0.01$ & $1.43 \pm 0.21$ & $>0.05$ & $1.31 \pm 0.17$ \\
\hline P90 BRT, s & $1.65 \pm 0.25$ & $<0.01$ & $2.72 \pm 0.94$ & $<0.01$ & $1.93 \pm 0.35$ & $>0.05^{*}$ & $1.70 \pm 0.23$ \\
\hline Mean LPD, cm & $28.8 \pm 5.3$ & $<0.01$ & $39.3 \pm 10.5$ & $>0.05$ & $34.4 \pm 9.1$ & $>0.05$ & $31.4 \pm 6.5$ \\
\hline P90 LPD, cm & $32.4 \pm 5.0$ & $<0.01$ & $48.8 \pm 16.3$ & $>0.05$ & $42.2 \pm 13.2$ & $>0.05^{*}$ & $37.2 \pm 8.9$ \\
\hline
\end{tabular}

All values are given as average $( \pm \mathrm{SD}$ ) of the means and the 90th percentiles. Statistical evaluation according to Student's $t$ test (one-tailed).

a These nonsignificant differences were even valid for comparison with the 10 preoperative controls, except for those marked.

b Patient No. 11 was not retested due to nausea.

reported remaining excessive daytime sleepiness, but none of the 15 subjects had persistence of the complete triad of symptoms characterizing SAS. However, in only 5 patients there was a more than $50 \%$ reduction of the number of sleep apneas observed.

BRT and LPD of untreated patients were significantly worse compared to control drivers (table 2), and 8 patients drove off the road compared to 1 of the controls
( $p<0.05$ ). The average 90th percentile BRT for patients was $1.1 \mathrm{~s}$ longer than for controls, corresponding to an extra $28 \mathrm{~m}$ to stop the vehicle at a speed of $90 \mathrm{~km} / \mathrm{h}$. Following surgical treatment the driving performance improved in most patients, whereas no improvement was noted for the retested controls. The improvement was thus significant for BRT (mean and 90th percentile). Similar changes were noted for LPD and off-road episodes, 
Table 3. Individual 90 th percentile results in BRT, LPD and offroad episodes before and after UPPP

\begin{tabular}{|c|c|c|c|c|c|c|}
\hline \multirow{2}{*}{$\begin{array}{l}\text { Patient } \\
\text { No. }\end{array}$} & \multicolumn{2}{|l|}{ BRT, s } & \multicolumn{2}{|c|}{$\mathrm{LPD}, \mathrm{cm}$} & \multicolumn{2}{|c|}{ Off-road episodes } \\
\hline & before & after & before & after & before & after \\
\hline 1 & 2.78 & 1.54 & 26.8 & 36.0 & 1 & 0 \\
\hline 2 & 2.13 & 1.96 & 59.7 & 51.4 & 6 & 1 \\
\hline 3 & - & - & 31.6 & 28.3 & 0 & 0 \\
\hline 4 & 1.92 & 1.96 & 46.1 & 43.6 & 0 & $1^{\mathrm{a}}$ \\
\hline 5 & 1.78 & 1.50 & 45.9 & 35.9 & 0 & 0 \\
\hline 6 & 2.48 & 1.62 & - & - & 0 & 0 \\
\hline 7 & 2.74 & 2.08 & 89.4 & 45.6 & 69 & 6 \\
\hline 8 & 2.64 & 2.30 & 56.3 & 71.3 & 8 & $27^{a}$ \\
\hline 9 & 2.40 & 2.00 & 41.5 & 34.8 & 5 & 0 \\
\hline 10 & 5.44 & 1.76 & 37.0 & 36.0 & 0 & 0 \\
\hline 11 & 4.52 & - & 34.8 & - & 0 & - \\
\hline 12 & 3.50 & 2.14 & 44.9 & 43.2 & 2 & 1 \\
\hline 13 & 2.70 & 2.68 & 62.0 & 60.9 & 3 & $4^{a}$ \\
\hline 14 & 2.80 & 2.12 & 37.8 & 40.5 & 0 & 0 \\
\hline 15 & 2.04 & 1.46 & 55.5 & 21.5 & 7 & 0 \\
\hline
\end{tabular}

BRT and LPD not analyzable in patients No. 3 and 6, respectively. Patient No. 11 was not retested due to nausea.

a Patients 4, 8 and 13 were clinical failures according to questionnaire.

however not significantly for the whole group. The average reduction of 90th percentile BRT corresponded to a reduction of stop distance of $20 \mathrm{~m}$ at the current speed.

Not all patients improved their driving performance after UPPP (table 3). In particular patients No. 4,8 , and 13 failed to improve and also showed off-road episodes at the retest. These 3 were the cases which independently were classed as clinical failures due to the questionnaire (table 1).

In the remaining, successfully treated cases, an average $35 \%$ decrease of the 90 th percentile BRT was noted,

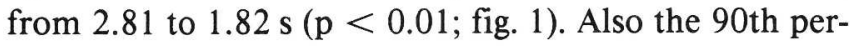
centile LPD improved significantly in the successfully treated group $(\mathrm{p}<0.05)$, and number of off-road episodes fell from 90 to $8(\mathrm{p}<0.05)$.

\section{Discussion}

Patients with clinical features of SAS and hypersomnia at the wheel drove worse than controls, but the essential message of the present study is that hypersomnia at the wheel and driving vigilance could be improved in most patients by UPPP.

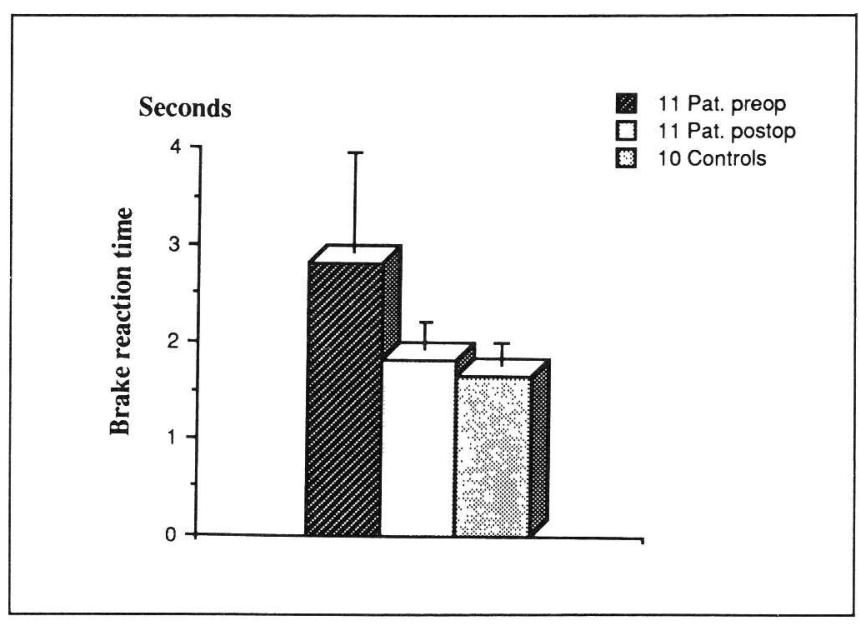

Fig. 1. Average BRT (90th percentile) for the $11 / 14$ retested, successfully treated cases pre- and postoperatively, compared to the 'preop' 10 controls. BRT \pm SD: $2.81 \pm 1.04,1.82 \pm 0.27,1.65 \pm$ 0.25 .

Objective data of 15 male patients' ability to cope with a monotonous simulator drive for $90 \mathrm{~min}$ was collected. Not only the mean value, but also the 90 th percentile was recorded, since it is at the extremes accidents tend to occur. All patients had multiple obstructive sleep apneas and SAS [8], although nap studies failed to prove it in 1 case (table 1). Very few comparisons have been made between daytime nap studies and all-night PSG. Guilleminault [18] found an increased AI on $4 / 5$ patients, whereas Fourre [19] found a significant decrease of AI in 6/6 patients compared to allnight PSG. Uncertainty in estimation of apnea index by napstudies might explain lack of correlation between driving performance and polysomnographic data in the present study. Nevertheless, there seems to be an association between improved driving performance and clinical improvement as indicated by the questionnaire. Decrease in sleep fragmentation [20] and less severe hypoxemia during sleep [3] may have led to improved driving vigilance. Three of 15 patients did not improve clinically according to the questionnaire (table 1). Two were heavily overweight and the other later admitted alcohol abuse at the current period of time, circumstances that may have impaired the outcome of surgery [21, 22].

Sleep apnea is one of the most common causes of excessive daytime sleepiness and sleep spells whilst driving [6]. During recent years demand for treatment of sleep apnea patients has increased, as the relationship between their disability and traffic hazard has become more apparent $[23,24]$. 
Driving simulator tests have recently been developed for objective measurements of driving performance in sleep apnea patients $[25,26]$. Findley et al. [26] used a Doron film simulator and an unsophisticated personal computor 'simulator'. The results indicate that the personal computor may be effective enough to detect driving impairment due to sleep apnea, and thus could be a valuable and inexpensive complementary method to evaluate driving vigilance. They could also demonstrate that nasal continuous positive airway pressure in sleep apnea drivers, improved driving performance [26].

Hypersomnia at the wheel is a common and dangerous complaint in drivers with the SAS [1,5]. This risk ratio for single car accidents in sleepy drivers with symptoms of the syndrome may be more than 10 times than that of others [1], indicating that they are unable to fully compensate for sleepiness by careful driving. Unlike other medical disorders causing unconsciousness at the wheel [27], hypersomnia due to SAS can easily be detected and treated.

\section{Acknowledgements}

Supported by grants from Folksam Research Foundation, The Memorial Foundation of Sigurd and Elsa Golje and from Karolinska Institute.

\section{References}

1 Haraldsson P-O, Carenfelt C, Diderichsen F, Nygren Å, Tingvall C: Clinical symptoms of sleep apnea syndrome and automobile accidents. ORL 1990;52:57-62.

2 Kales A, Caldwell AB, Cadieux RJ, Vela-Bueno A, Ruch LG, Mayes SD: Severe obstructive sleep apnoea-II: Associated psychopathology and psychosocial consequences. J Chronic Dis 1985;38:427-434.

3 Findley LJ, Barth JT, Powers DC: Cognitive impairment in patients with obstructive sleep apnea and associated hypoxemia. Chest 1986;90:686-690.

4 George CF, Nickerson PW, Hanly PJ, Millar TW, Kryger MH: Sleep apnoea patients have more automobile accidents (Letter). Lancet 1987;ii:447.

5 Findley J. Unverzagt ME, Suratt M: Automobile accidents involving patients with obstructive sleep apnea. Am Rev Respir Dis 1988;138:337-340.

6 Aldrich M, Aldrich K, Kehn T: Automobile accidents: Relation to excessive daytime sleepiness (abstract 399). 5th Int Congr Sleep Res, Copenhagen 1987.

7 Guilleminault C, van den Hoed J, Mitler M: Clinical overview of the sleep apnea syndrome; in Guilleminault C, Dement W (eds): Sleep Apnea Syndromes. New York, Liss, 1978, pp 1-12.

8 Roffwarg H, et al: Association of Sleep Disorders Centers. Diagnostic classification of sleep and arousal disorders. Sleep 1979; 2(1):1-137.
9 Fujita S: UPPP for sleep apnea syndrome. Ear Nose Throat J 1984;63:73-86.

10 Dickson RI, Blokmanis A: Treatment of obstructive sleep apnea by uvulopalatopharyngoplasty. Laryngoscope 1987;97:10541059.

11 Macaluso R, Reams C, Gibson W, Vrabec D, Matragrano A: Uvulopalatpharyngoplasty: Postoperative management and evaluation of results. Ann Otol Rhinol Laryngol 1989;98:502507.

12 Haraldsson P-O, Carenfelt C, Laurell H, Törnros J: Driving vigilance simulator test. Acta Otolaryngol (Stockh) 1990;110:136140.

13 Kales A, Cadiuex RJ, Bixler EO, et al: Severe obstructive sleep apnea. 1. Onset, clinical course, and characterstics. J Chronic Dis 1985;38:419-425.

14 Riley R, Guilleminault C, Powell N, Simmons FB: Palatopharyngoplasty failure, cephalometric roentgenograms, and obstructive sleep apnea. Otolaryngol Head Neck Surg 1985;93:240243.

15 Fairbanks D, Fujita S, Ikematsu T, Simmons FB: Snoring and Obstructive Apnea. New York, Raven Press, 1987, pp 116120.

16 Keys A, Fidanza F, Karvonen MI, Kimura N, Taylor HL: Indices of relative weight and obesity. J. Chronic Dis 1972;25: 329-343.

17 Goode B, Slyter H: Daytime polysomnogram diagnosis of sleep disorders. J Neurol Neurosurg Psychiatry 1983;46:159-161.

18 Guilleminault C: Sleep apnea syndromes: Impact of sleep and sleep states. Sleep 1980;3(3/4):227-234.

19 Fourre J, Scoles V, Nahmias J, Karetzky MS: The use of nap studies in diagnosing sleep apnea. Sleep Res 1986;15:122.

20 Bonnet MH: Effect of sleep disruption, performance and mood. Sleep 1985;8:11-19.

21 Gislason T, Lindholm C-E. Almqvist M, Birring E, Boman G, et al: Uvulopalatoplasty in the sleep apne syndrome. Predictors of Results. Arch Otolar Head Neck Surg 1988;114:45-51.

22 Issa FQ, Sullivan CE: Alcohol, snoring and sleep apnea. J Neurol Neurosurg Psychiatry 1982;45:353-359.

23 Findley L, Bonnie LL: Sleep apnea and auto crashes - what is the doctor to do? Chest 1988;94:225-226.

24 Stradling JR: Obstructive sleep apnea and driving - sufferers need medical advice. Br Med J 1989;298:904-905.

25 Haraldsson P-O, Carenfelt C, Laurell H, Nygren $\AA$, Tingvall C, Törnros J: Driving performance and single car accidents among drivers with symptoms of sleep apnea syndrome (Abstract 409). First World Conf Accident Injury Prevent, Stockholm 1989.

26 Findley L, Fabrizio M, Knight H, Norcross B, Laforte A, Suratt P: Driving simulator performance in patients with sleep apnea. Am Rev Respir Dis 1989;140:529-530.

27 Parson M: Fits and other causes of loss of consciousness while driving. Q J Med 1986;227:295-303.

Received: July 10, 1990

Accepted: July 19, 1990

Dr. P.-O. Haraldsson

Department of Otorhinolaryngology

Karolinska Hospital

S-10401 Stockholm (Sweden) 




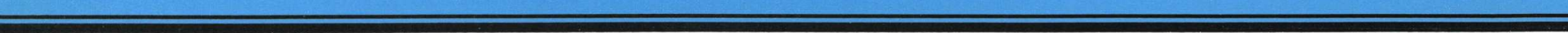

